\title{
Killing two birds with one stone: $B R A F$ V600E inhibitor therapy for hairy cell leukemia and Langerhans/dendritic cell sarcoma
}

\author{
Vivek Subbiah • Ishwaria Mohan Subbiah
}

Received: 3 January 2013 / Accepted: 8 January 2013 /Published online: 16 January 2013

(C) Springer-Verlag Berlin Heidelberg 2013

\section{Dear Editor,}

We read with great interest the article published in Annals of Hematology on a patient with Langerhans/dendritic cell sarcoma arising from hairy cell leukemia with both lesions demonstrating almost identical karyotypes and identical clonal immunoglobulin gene rearrangements [1]. This case is very interesting in light of fresh data on BRAF V600E mutations in several different tumor types [2].

Whole exome sequencing of patients with hairy cell leukemia has revealed BRAF V600E mutation [3]. This BRAFV600E mutation has been described as a diseasedefining event [3] in hairy cell leukemia and has been implicated in the pathogenesis of hairy cell leukemia. Langerhans cell histiocytoses have also been reported to harbor the BRAFV600E mutation [4]. Histiocytoses are extremely rare diseases with variable clinical syndromes and BRAFV600E mutations have been reported in multiple histiocytoses subtypes including Erdheim-Chester disease [5].

In the light of these results, the case reported is very fascinating [1]. It may be interesting to profile the BRAFV600E status of the hairy cell leukemic clone and the histiocytic/dendritic sarcoma clone. If confirmed, this could suggest clonality and may also indicate a common origin of these diverse rare diseases. Moreover, for this particular patient this may have implications for targeted therapy. Vemurafenib, a $B R A F$ inhibitor has been recently Food and Drug Administration approved for the therapy of BRAFV600E mutant metastatic melanoma [6]. Although hairy cell leukemia is a treatable disease with standard regimens, rare relapsed patients could still benefit from BRAF inhibitor targeted therapy and a proof of concept study has already been reported [7]. Some patients with Langerhans cell histocytoses may have an aggressive clinical course and patients with refractory disease may have few options. $B R A F$ inhibitor-targeted therapy may be the way to kill two birds with one stone such as in this patient if BRAFV600E mutation is confirmed.

Conflict of interest The authors declare that they have no conflict of interest

\section{References}

1. Muslimani A, Chisti MM, Blenc AM et al (2012) Langerhans/ dendritic cell sarcoma arising from hairy cell leukemia: a rare phenomenon. Ann Hematol 91:1485-1487

2. Davies H, Bignell GR, Cox C et al (2002) Mutations of the BRAF gene in human cancer. Nature 417:949-954

3. Tiacci E, Trifonov V, Schiavoni G et al (2011) BRAF mutations in hairy-cell leukemia. N Engl J Med 364:2305-2315

4. Badalian-Very G, Vergilio JA, Degar BA et al (2010) Recurrent BRAF mutations in Langerhans cell histiocytosis. Blood 116:1919-1923

5. Haroche J, Charlotte F, Arnaud L et al (2012) High prevalence of BRAF V600E mutations in Erdheim-Chester disease but not in other non-Langerhans cell histiocytoses. Blood 120:2700-2703

6. Chapman PB, Hauschild A, Robert C et al (2011) Improved survival with vemurafenib in melanoma with BRAF V600E mutation. N Engl J Med 364:2507-2516

7. Dietrich S, Glimm H, Andrulis M et al (2012) BRAF inhibition in refractory hairy-cell leukemia. N Engl J Med 366:2038-2040
V. Subbiah $(\bowtie) \cdot$ I. M. Subbiah

Department of Investigational Cancer Therapeutics, Division of Cancer Medicine, MD Anderson Cancer Center, The University of Texas MD Anderson Cancer Center, Unit 455, 1515 Holcombe Boulevard,

Houston, TX 77030-4009, USA

e-mail: vsubbiah@mdanderson.org 